\title{
Lead-Silver Anode Degradation during Zinc Electrorecovery Process: Chloride Effect and Localized Damage
}

\author{
Mohsen Lashgari ${ }^{1,2}$ and Farzaneh Hosseini' \\ ${ }^{1}$ Department of Chemistry, Institute for Advanced Studies in Basic Sciences (IASBS), Zanjan 45137-66731, Iran \\ ${ }^{2}$ Center of Climate Changes and Global Warming (CCCGW), Institute for Advanced Studies in Basic Sciences (IASBS), \\ Zanjan 45137-66731, Iran
}

Correspondence should be addressed to Mohsen Lashgari; lashgari@iasbs.ac.ir

Received 4 May 2013; Revised 1 September 2013; Accepted 18 September 2013

Academic Editor: Aicheng Chen

Copyright (C) 2013 M. Lashgari and F. Hosseini. This is an open access article distributed under the Creative Commons Attribution License, which permits unrestricted use, distribution, and reproduction in any medium, provided the original work is properly cited.

Using mass-loss, potentiodynamic polarization, and electrochemical impedance measurements under anodic regime, the corrosion behaviour of lead-silver $(0.55 \%)$ electrode in zinc electrowinning solution containing different concentration of chloride anions was studied. The results revealed that the rate of corrosion does not monotonically increase with concentration. Moreover, the maximum degradation occurs at the concentration where the anodic process (oxygen evolution) proceeds hardly. According to polarization curves, the electrode exhibited obvious electrocatalytic activity (for anode reaction) by forming oxide layer. To scrutinize the localized damage, occurring at the bottom of anode, we also took some scanning electron micrographs with energy dispersive $\mathrm{X}$-ray analyses. The investigations suggested a new mechanism, that is, a complicated migration phenomenon, resulting from an electrodissolution/sedimentation/deposition process.

\section{Introduction}

The electroextraction of zinc metal from its ores is accomplished through an industrial roasting-leachingelectrorecovery process [1], which is succinctly referred to as electrowinning. During this hydrometallurgical/ electroextraction process, by passing DC current through the resulting electrolytic (leach) solution, the zinc (II) cations are electrodeposited upon the aluminum cathodes; the aluminum is applied [2] because it is light and has poor tendency to alloying/adhering with zinc atoms, thus, facilitating the handling and stripping of the cathodes from their zinc products at the end of duty. The anodes of the electrowinning cells, however, are fabricated from lead and its alloys. This is also because of $\mathrm{PbO}_{2}$ layer being formed upon the electrode surface under the anodic regimes [3, 4]. The layer is passive against corrosion but yet acts as a good electron conductor for faradic $e$-transfer process [5]. The anodic process occurring here is an oxygen evolution reaction, being electrocatalyzed by adding silver component to the anode composition $[6,7]$.
Besides the alloying components, the presence of additives in the electrolyte solution is another issue that should be accounted for. Chloride anion is one of the additives that is important from corrosion standpoint [8]. The anion leads to the localized damage of metals through specific adsorption and dissolution of the metals' passive layer [9]. Under anodic load, we believe that the mechanism of damage is rather complicated, needing extra scrutiny. In the present work, we have focussed on this issue with attempting to provide a new mechanistic insight for localized damage occurring at the bottom of anodes, during the zinc electrowinning process.

\section{Experimental Details}

The electrochemical cell used for mass-loss experiments was a handmade polyethylene electrowinning cell $(15 \times$ $12 \times 18 \mathrm{~cm}$ ), presented in Figure 1 . The cathode and anode applied here were aluminum and lead plates $(90 \times 30 \times$ $4 \mathrm{~mm}$ ) cut from commercially available pure $\mathrm{Al}$ and $\mathrm{Pb} / \mathrm{Ag}$ sheets with the following anode composition (wt. \%, determined by quantometric analysis): $\mathrm{Pb}$ (99.430), Ag (0.553), 


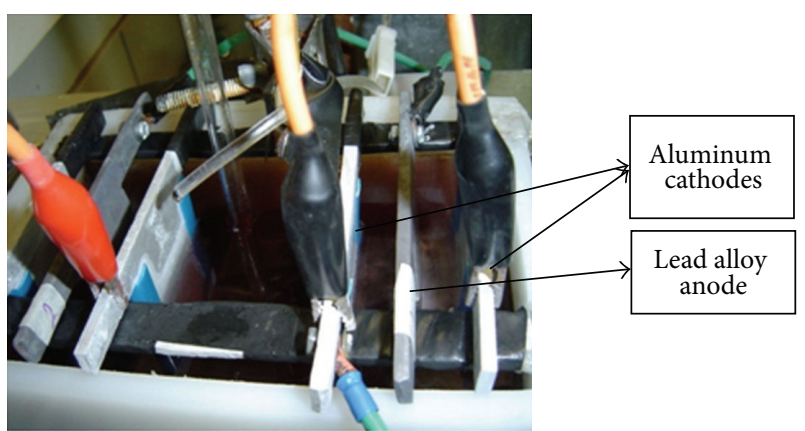

Figure 1: The electrorecovery cell with T-shape electrodes under load.

Bi (0.0069), Cu (0.0049), S (0.0014), Ca (0.0006), Zn (0.0005), Fe (0.0003), and other impurities in trace. Before use in the cell, the surface of electrodes (anodes) was abraded with successive emery papers numbers 180, 220, $400,600,800$, and 1200 , followed by etching in a mixture of acetic acid and hydrogen peroxide [10], prepared from $3: 1$ volume ratio of the acid (96\%) and oxygenated water (34\%). The electrodes were washed with deionized water and dried by hot air. After weighing, the electrodes were set in the cell and spaced ca. $1.5 \mathrm{~cm}$ apart. The cell was then filled by the electrolyte with the following composition: $43 \mathrm{~g} / \mathrm{L} \mathrm{Zn}^{2+}, 124 \mathrm{~g} / \mathrm{L} \mathrm{H}_{2} \mathrm{SO}_{4}, 2.5 \mathrm{~g} / \mathrm{L} \mathrm{Mn}^{2+}, 3.7 \mathrm{ppm} \mathrm{Pb}{ }^{2+}$, $14 \mathrm{ppm} \mathrm{Fe}{ }^{2+}, 185 \mathrm{ppm} \mathrm{Cl}^{-}, 722.5 \mathrm{ppm} \mathrm{Mg}^{2+}, 29.9 \mathrm{ppm} \mathrm{Ca}^{2+}$, $2.2 \mathrm{ppm} \mathrm{Cd}^{2+}, 0.2 \mathrm{ppm} \mathrm{Cu}^{2+}$, and $0.1 \mathrm{ppm} \mathrm{Co}^{2+}$ (a typical feed of zinc electrowinning industries in Zanjan province). During the electrowinning process, the level of electrolyte and the concentration of zinc cation were fixed using a makeup solution, flowing in through the bottom and out from the top of the cell (flux rate $\approx 3.2 \mathrm{~mL} / \mathrm{min}$; $\left[\mathrm{Zn}^{2+}\right]$ $=75 \mathrm{~g} / \mathrm{L}$ ). Similar to industrial conditions, the temperature of electrolyte was set to $40^{\circ} \mathrm{C}$ using a Memmert digital bath $\left( \pm 1^{\circ} \mathrm{C}\right)$. The electrorecovery of zinc was performed at a constant current density $\left(500 \mathrm{~A} / \mathrm{m}^{2}\right)$ with a MEGATEK double rectifier (MP-3005D). After each $24 \mathrm{~h}$, the process was interrupted, and the zinc product was detached from the surface of the cathodes. For the lead-alloy anodes, the corrosion product was removed by dipping them into a hot/boiling $\mathrm{NaOH}(20 \%)$ solution [11]. Then, the anodes were washed with deionized water, dried, and finally weighed with a Sartorius analytical balance (BL210S).

For electrochemical studies, a three-electrode Metrohm glass cell attached to a Lauda/ecolineRE104 circulator was used. The electrodes were platinum foil $\left(2.5 \mathrm{~cm}^{2} ; \mathrm{AE}\right)$, mercury/mercury chloride (saturated calomel; RE), and leadsilver alloy (mounted in epoxy resin, $4 \times 5 \mathrm{~mm}$; WE). The electrochemical experiments (polarization and impedance) were carried out using an AUTOLAB/PGSTAT100 instrument, running with GPES/FRA software (ECO CHEMIE). The polarization plots were obtained at the scan rate $20 \mathrm{mV}$ per $500 \mathrm{sec}$ [12]. For impedance measurements (EIS, electrochemical impedance spectroscopy) [13], the amplitude of the AC signal was $10 \mathrm{mV}$, and the frequency range was set from $500 \mathrm{kHz}$ to $5 \mathrm{mHz}$.
TABLE 1: Corrosion rate (CR) of the lead/silver, measured gravimetrically in zinc electrowinning solutions containing different chloride concentrations $\left(t=72 \mathrm{hr}, i=500 \mathrm{Am}^{-2}\right.$, and $\left.T=40^{\circ} \mathrm{C}\right)$.

\begin{tabular}{lcc}
\hline$(\mathrm{Cl}) / \mathrm{ppm}$ & $\mathrm{CR}\left(\mathrm{gr} \cdot \mathrm{m}^{-2} \mathrm{~h}^{-1}\right)$ & $\begin{array}{c}\text { Impurity of lead in the } \\
\text { cathode's product }(\%)^{\mathrm{a}}\end{array}$ \\
\hline 130 & 2.80 & 0.1407 \\
175 & 3.06 & 0.1666 \\
280 & 2.92 & 0.1285 \\
380 & 2.32 & 0.1155 \\
\hline
\end{tabular}

${ }^{a}$ Obtained from atomic absorption experiments (see Section 2).

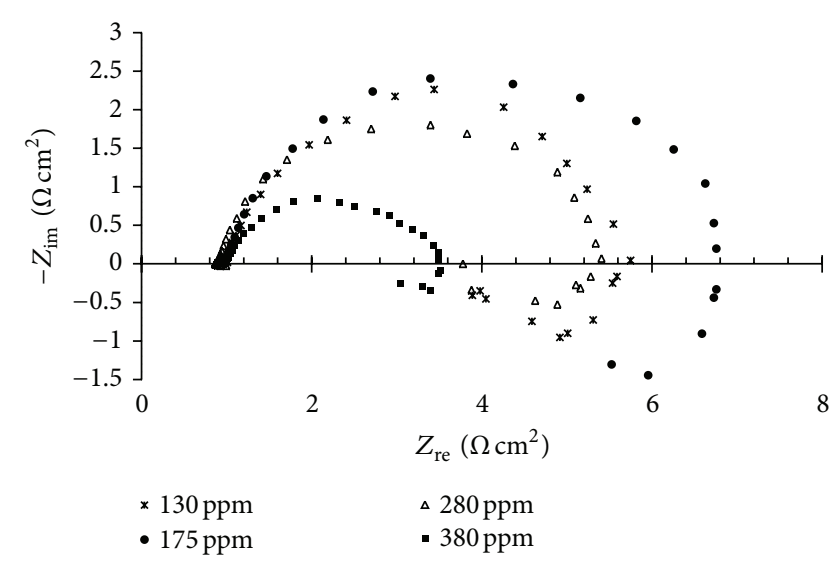

Figure 2: Nyquist diagrams of $\mathrm{Pb}-\mathrm{Ag}$ electrode under anodic polarization regime in the electrowinning solution with different chloride contents $\left(i=500 \mathrm{~A} / \mathrm{m}^{2}, T=40^{\circ} \mathrm{C}\right)$.

Besides electrochemical studies, the surface morphology of the anode after 72 hours electrowinning was examined ex situ by a SEM VEGA TESCAN electron microscope equipped with an energy-dispersive spectrometer (EDS) [14]. The lead contamination of the cathode's product $(\mathrm{Zn})$ was also determined according to the ASTM E536 protocol [15] using a Perkin Elmer AA300 atomic absorption spectrometer.

\section{Results and Discussion}

The rate of electrode degradation under anodic regime was determined through mass-loss experiments, using this formula as follows [16]:

$$
\mathrm{CR}=\frac{\Delta M}{A \times t},
$$

where $\Delta M$ (gr) is the extent of degradation (mass-loss), $t$ time of process $(\mathrm{hr})$, and $A\left(\mathrm{~m}^{2}\right)$ surface area of the anode exposed to the electrolyte solution. Table 1 represents the results of these investigations, obtained at different chloride concentrations. As it can be seen from this table, the rate of corrosion does not monotonically increase with chloride content. The degradation is maximized at $\left[\mathrm{Cl}^{-}\right]$ $=175 \mathrm{ppm}$. At this concentration, the greatest $\mathrm{Pb}$ impurity of the cathode's product (zinc) is observed. The maximum degradation observed at $175 \mathrm{ppm}$ is also confirmed through impedance spectra, depicted in Figure 2; the plots indicate 


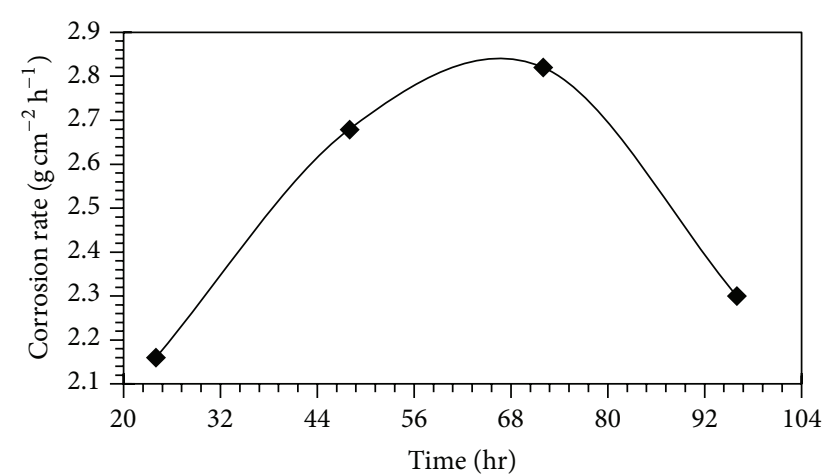

FIgURE 3: The rate of anode degradation at different time intervals during the electrowinning process, obtained at current density $500 \mathrm{~A} / \mathrm{m}^{2}$ via mass-loss measurements $\left(T=40^{\circ} \mathrm{C}\right)$.

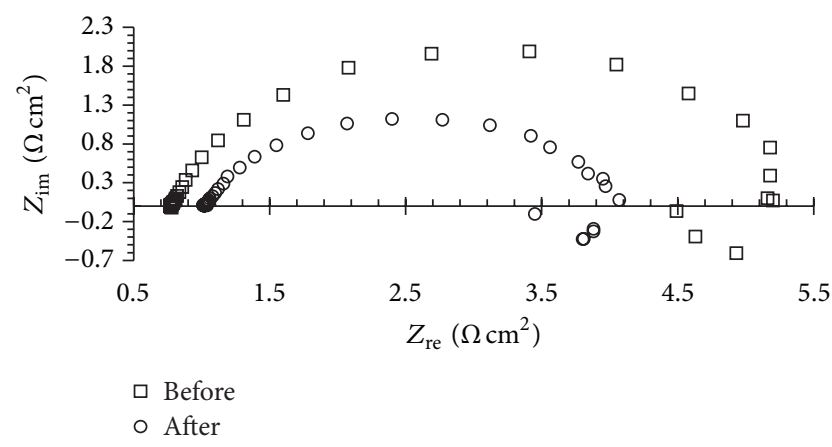

FIgURE 4: Impedance plots of $\mathrm{Pb} / \mathrm{Ag}$ anode before and after oxide layer formation upon the electrode surface $\left(i=500 \mathrm{~A} / \mathrm{m}^{2}, T=\right.$ $\left.40^{\circ} \mathrm{C}\right)$.

that the greatest resistance against charge transfer reaction ( $R_{\mathrm{ct}}$; the diameter of semicircle) is concerned with this concentration. In addition, the anodic reaction at $\left[\mathrm{Cl}^{-}\right]=380$ ppm proceeds with its maximum velocity and corresponds with the lowest degree of damage (CR). To justify these observations, it should be notified that the chloride anion is a well-known corrosive (pitting) agent. In the presence of chloride, the rate of corrosion is expectedly increased with the anion concentration. After $175 \mathrm{ppm}$, by facilitating the oxygen evolution reaction (notice the diameter of semicircles presented in Figure 2), the formation of oxide protective layer becomes enhanced [3] and the rate of corrosion becomes consequently decreased.

At initial stages of the process, since there is no significant $\mathrm{PbO}_{2}$ layer upon the anode surface, the electrode is not protected and degraded easily (see Figure 3 ). The surface of anode will be, however, protected by forming oxide layer, and the rate of degradation will be consequently decreased. The layer formation causes the impedance of system to be diminished, and the faradic process is facilitated; see Figure 4: the diameter of semicircle decreased due to electrocatalytic characteristics of $\mathrm{PbO}_{2}$ layer. The facilitation of oxygen evolution reaction is also confirmed by anodic potentiodynamic polarization plots depicted in Figure 5. The diagram obviously illustrates the electrocatalyzing influence of the $\mathrm{Ag}$

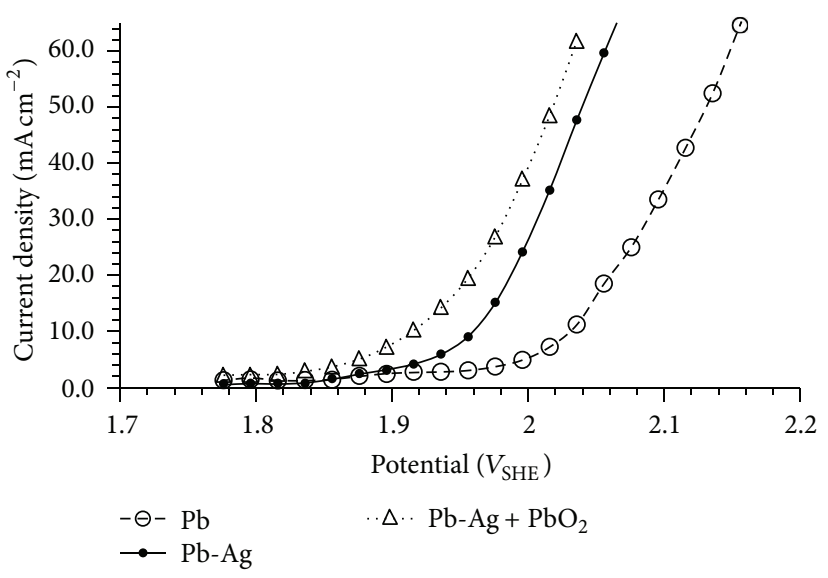

FIGURE 5: Potentiodynamic behavior of lead and its alloy (0.55\% Ag) in zinc electrowinning solution at $40^{\circ} \mathrm{C}$. (a) $\mathrm{Pb}$, (b) $\mathrm{Pb}-\mathrm{Ag}$, and (c) $\mathrm{Pb}-\mathrm{Ag}$ covered with $\mathrm{PbO}_{2}$ film.

component on the oxygen evolution reaction. This is why in the present work we have chosen the lead-silver alloy as the anode instead of the pure lead metal.

The another issue, which is worthy of notification, is the nonuniform localized corrosion occurring more probably at the bottom of the anode. The phenomenon seems to be related to the low resistance of the metal's atoms creeping down, which causes the moving of atoms being boosted by the gravity force (strain) under current passage through the electrode [17]. Thus, the thickness of anode increases by going downward. Correspondingly, because the space between anode and cathode $(l)$ diminishes, the current passage and hence the current density $(i=I / A)$ are increased at particular zones by decreasing the electrolyte resistance ( $R=\rho(l / A) ; \rho$ and $A$ are fixed, whereas $l$ is diminished). So, it more probably leads to the short circuit and results in the localized corrosion [18]. Figure 6 illustrates the SEM images of the anode before and after the electrowinning process; Figure 6(d) shows the micrograph of the area damaged locally after 72 hours of electrowinning. Furthermore, Figures 6(b) and $6(\mathrm{c})$ are related to the other parts of the anode. The nonuniform distribution of $\mathrm{Ag}$ component upon the anode surface is also seen in Figure 6(a).

To determine the composition of anode, we performed EDS analyses. The results are given in Table 2. The table indicates that during the electrowinning process (Figures 6(b), 6(c), and 6(d)) manganese cations are deposited on the anode surface $\left(\mathrm{Mn}^{2+}\right.$ is oxidized to manganese (IV) oxide, a darkbrown product). Therefore, some area of the anode becomes enriched with manganese, and a protective/smooth layer is formed; see Figure 6(c). Table 2 also shows an enrichment for silver atoms at the damaged area (Figure 6(d)); the zone has partly a dendrite-like morphology, which is the characteristic of the silver-containing systems [19]. The occurrence of localized damage and accumulation of silver and oxygen atoms therein can be interpreted through this electrooxidative dissolution/sedimentation/deposition mechanism.

During the electrowinning process, the silver atoms are anodically dissolved as $\mathrm{Ag}^{+}$cations. The cations react 


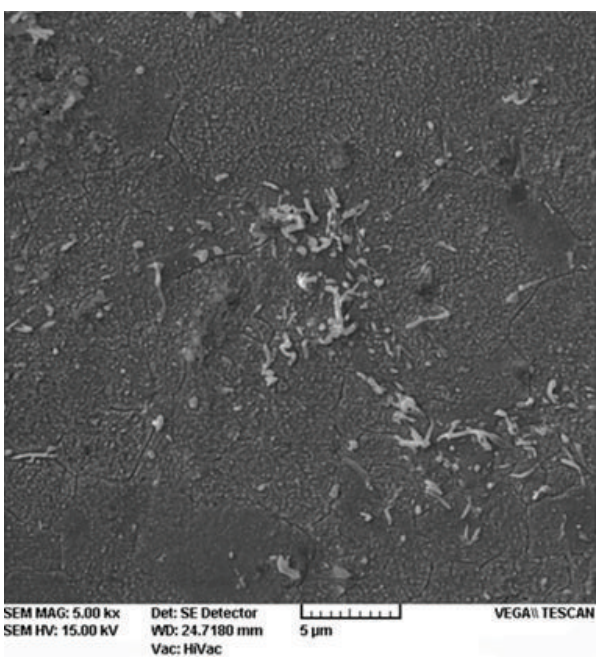

(a)

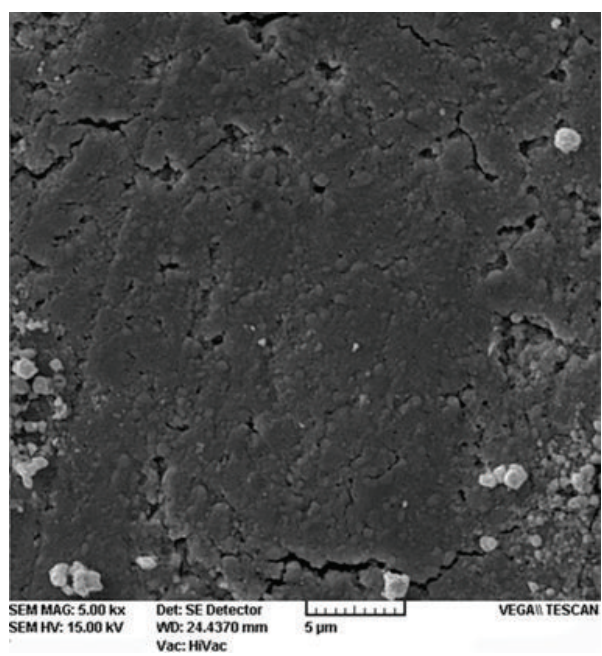

(c)

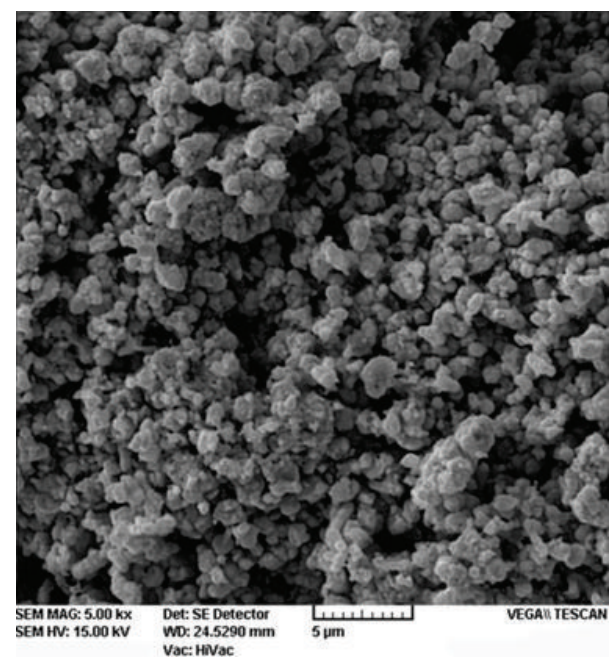

(b)

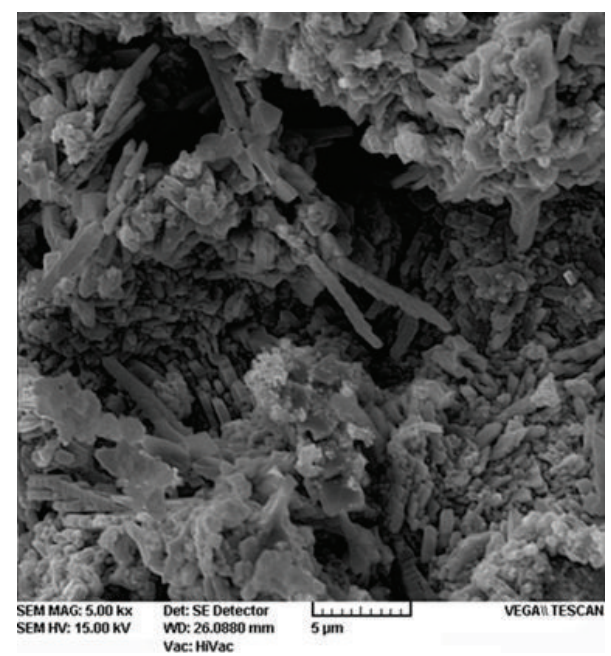

(d)

FIGURE 6: SEM micrographs of lead/silver anodes before (a) and after 72 hours electrowinning process ((b)), (c), (d)). The image (d) is taken from the bottom of electrode, which corresponds with the localized damaged area.

with hydroxide anions already generated at the cathode surface $\left(\mathrm{H}_{2} \mathrm{O} \rightarrow \mathrm{H}_{2} \uparrow+\mathrm{OH}^{-}\right)$; therefore, a colloidal AgOH will be produced and gradually precipitated downward. At the bottom of the anode, where the current density is high, the hydroxide component of the colloids can undergo reoxidization, followed by the cations redeposition as silver oxide under giant electric field of the interface [20]:

$$
\begin{gathered}
4 \mathrm{AgOH} \longrightarrow 4 \mathrm{Ag}^{+}+\mathrm{O}_{2}+2 \mathrm{H}_{2} \mathrm{O}+4 \mathrm{e}^{-} \\
4 \mathrm{Ag}^{+}+4 \mathrm{e}^{-}+\mathrm{O}_{2} \longrightarrow 2 \mathrm{Ag}_{2} \mathrm{O} \\
4 \mathrm{AgOH} \longrightarrow 2 \mathrm{Ag}_{2} \mathrm{O}+2 \mathrm{H}_{2} \mathrm{O}
\end{gathered}
$$

This mechanism justifies why the extent of oxygen and silver elements becomes high at the damaged zones.
TABLE 2: EDS data of lead/silver (0.55\%) anode before and after $72 \mathrm{hr}$ of electrowinning process, obtained at different areas (see Figure 6).

\begin{tabular}{lcccc}
\hline Area & $\mathrm{Pb}(\%)$ & $\mathrm{Ag}(\%)$ & $\mathrm{O}(\%)$ & $\mathrm{Mn}(\%)$ \\
\hline Figure 6(a) & 95.60 & 3.98 & - & - \\
Figure 6(b) & 98.16 & 0.62 & 0.74 & 0.48 \\
Figure 6(c) & 97.63 & 0.76 & 0.76 & 0.85 \\
Figure 6(d) & 97.11 & 1.00 & 1.09 & 0.44 \\
\hline
\end{tabular}

\section{Conclusion}

Using the present mechanistic approach, the following points are concluded.

(i) By catalyzing the oxygen evolution reaction, the formation of lead oxide upon the lead anode surface 
becomes facilitated, and the rate of corrosion is consequently decreased.

(ii) The degradation of anode does not monotonically increase with chloride content in the electrolyte solution.

(iii) During the electrowinning process, the localized corrosion most probably occurred at the bottom of anode, and the damaged zone is enriched with silveralloying component, migrated through a complex electrooxidative dissolution/sedimentation/deposition mechanism.

\section{Acknowledgment}

Farzaneh Hosseini would like to thank "the Iranian Zinc Mines Development Company (IZMDC)" for partial financial support and lab facility.

\section{References}

[1] R. Raghavan, P. K. Mohanan, and S. K. Verma, "Modified zinc sulphate solution purification technique to obtain low levels of cobalt for the zinc electrowinning process," Hydrometallurgy, vol. 51, no. 2, pp. 187-206, 1999.

[2] A. Recéndiz, I. González, and J. L. Nava, "Current efficiency studies of the zinc electrowinning process on aluminum rotating cylinder electrode (RCE) in sulfuric acid medium: influence of different additives," Electrochimica Acta, vol. 52, no. 24, pp. 6880-6887, 2007.

[3] T. Nguyen and A. Atrens, "Composition and morphology of the film formed on a lead alloy under conditions typical of the electro-winning of copper," Hydrometallurgy, vol. 96, no. 1-2, pp. 14-26, 2009.

[4] C. Rerolle and R. Wiart, "Kinetics of $\mathrm{Pb}$ and $\mathrm{PbAg}$ anodes for zinc electrowinning-I: formation of $\mathrm{PbSO}_{4}$ layers at low polarization," Electrochimica Acta, vol. 40, no. 8, pp. 939-948, 1995.

[5] A. Felder and R. D. Prengaman, "Lead alloys for permanent anodes in the nonferrous metals industry," JOM, vol. 58, no. 10, pp. 28-31, 2006.

[6] C. Rerolle and R. Wiart, "Kinetics of oxygen evolution on $\mathrm{Pb}$ and $\mathrm{Pb}-\mathrm{Ag}$ anodes during zinc electrowinning," Electrochimica Acta, vol. 41, no. 7-8, pp. 1063-1069, 1996.

[7] C. Cachet, C. Rerolle, and R. Wiart, "Kinetics of $\mathrm{Pb}$ and $\mathrm{Pb}-\mathrm{Ag}$ anodes for zinc electrowinning-II: oxygen evolution at high polarization," Electrochimica Acta, vol. 41, no. 1, pp. 83-90, 1996.

[8] R. H. Newnham, "Corrosion rates of lead based anodes for zinc electrowinning at high current densities," Journal of Applied Electrochemistry, vol. 22, no. 2, pp. 116-124, 1992.

[9] E. McCafferty, "Sequence of steps in the pitting of aluminum by chloride ions," Corrosion Science, vol. 45, no. 7, pp. 1421-1438, 2003.

[10] H. Takasaki and Watanabe Metals Ltd, International Symposium on Lead and Zinc Processing, Durban, South Africa, 2008.

[11] S. Rashkov, T. Dobrev, Z. Noncheva, Y. Stefanov, B. Rashkova, and M. Petrova, "Lead-cobalt anodes for electrowinning of zinc from sulphate electrolytes," Hydrometallurgy, vol. 52, no. 3, pp. 223-230, 1999.
[12] C. Cachet, C. Le Pape-Rérolle, and R. Wiart, "Influence of $\mathrm{Co}^{2+}$ and $\mathrm{Mn}^{2+}$ ions on the kinetics of lead anodes for zinc electrowinning," Journal of Applied Electrochemistry, vol. 29, no. 7, pp. 813-820, 1999.

[13] M. Lashgari, M. Arshadi, and S. Miandari, "The enhancing power of iodide on corrosion prevention of mild steel in the presence of a synthetic-soluble Schiff-base: electrochemical and surface analyses," Electrochimica Acta, vol. 55, no. 20, pp. 60586063, 2010.

[14] M. Lashgari and M. Osanloo, "Mechanistic studies of the synergistic effect: copper corrosion in $\mathrm{HCl}$ medium in the presence of a synthetic/eco-friendly inhibitor," International Review of Biophysical Chemistry, vol. 2, pp. 1-8, 2011.

[15] ASTM E536-08, Standard Test Methods for Chemical Analysis of Zinc and Zinc Alloys, ASTM International, West Conshohocken, $\mathrm{Pa}, \mathrm{USA}, 2008$.

[16] M. Lashgari, M. Arshadi, and M. Biglar, "Comparative studies of some heterocyclic compounds as corrosion inhibitors of copper in phosphoric acid media," Chemical Engineering Communications, vol. 197, no. 10, pp. 1303-1314, 2010.

[17] M. Taguchi, J. Tanaka, T. Bundo, R. Itou, and K. Shirai, "In situ analysis of creep behavior of pure $\mathrm{Pb}$ using electrochemical creep system," Journal of Power Sources, vol. 196, no. 1, pp. 470474, 2011.

[18] J. A. Gonzales, J. Rodrigues, and A. Siegmund, "Advances and application of lead alloy anodes for zinc electrowinning," in Lead and Zinc '05, T. Fujisawa, Ed., vol. 2, pp. 1037-1059, MMIJ, 2005.

[19] J. Fang, H. You, C. Zhu et al., "Thermodynamic and kinetic competition in silver dendrite growth," Chemical Physics Letters, vol. 439, no. 1-3, pp. 204-208, 2007.

[20] M. Lashgari, M. R. Arshadi, and V. S. Sastri, "Quantum electrochemical approaches to corrosion inhibition properties of some aniline derivatives in acidic media," Journal of the Electrochemical Society, vol. 154, no. 8, pp. P93-P100, 2007. 

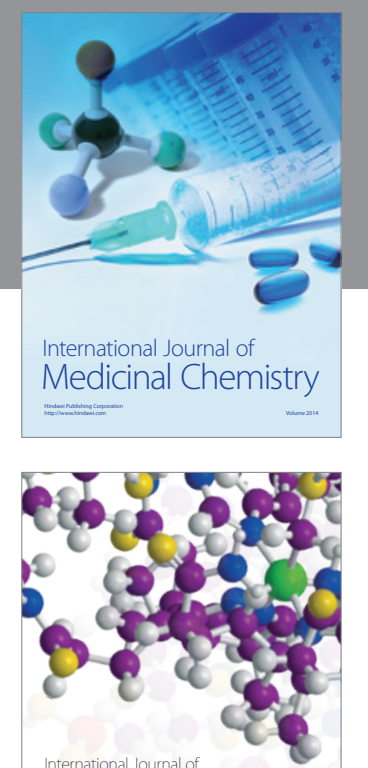

\section{Carbohydrate} Chemistry

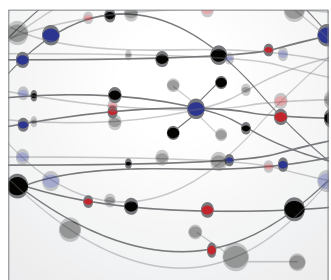

The Scientific World Journal
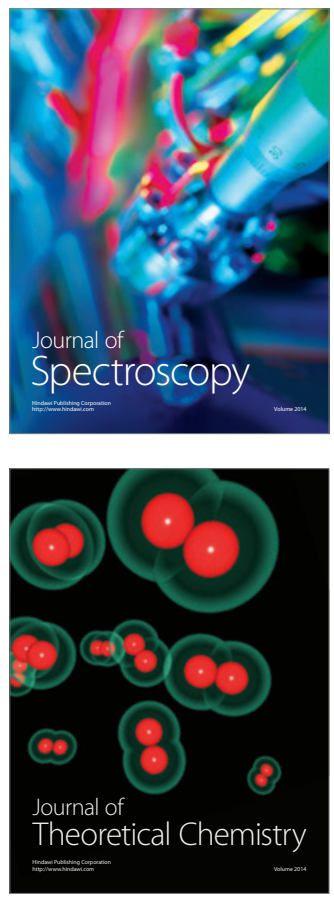
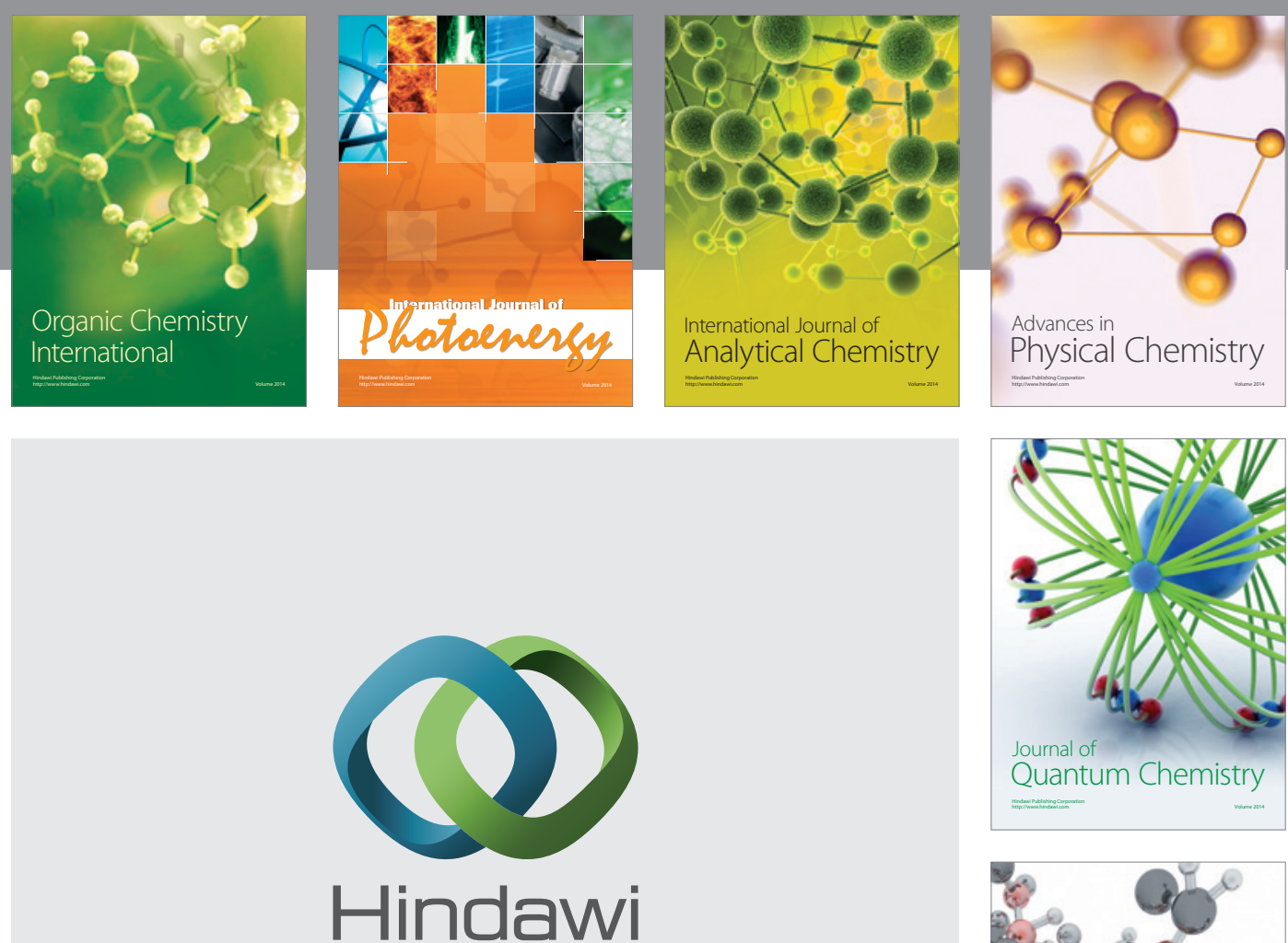

Submit your manuscripts at

http://www.hindawi.com

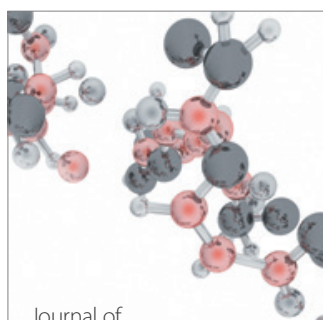

Analytical Methods

in Chemistry

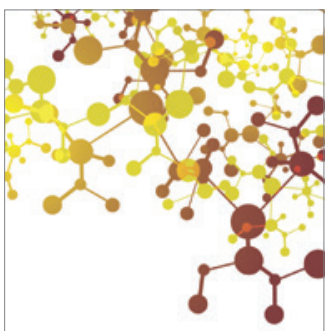

Journal of

Applied Chemistry

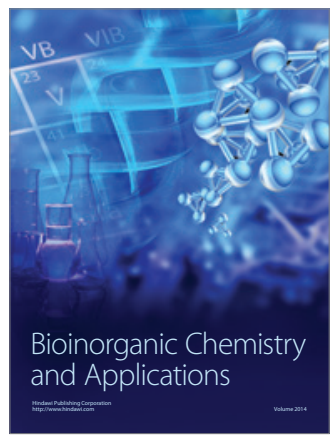

Inorganic Chemistry
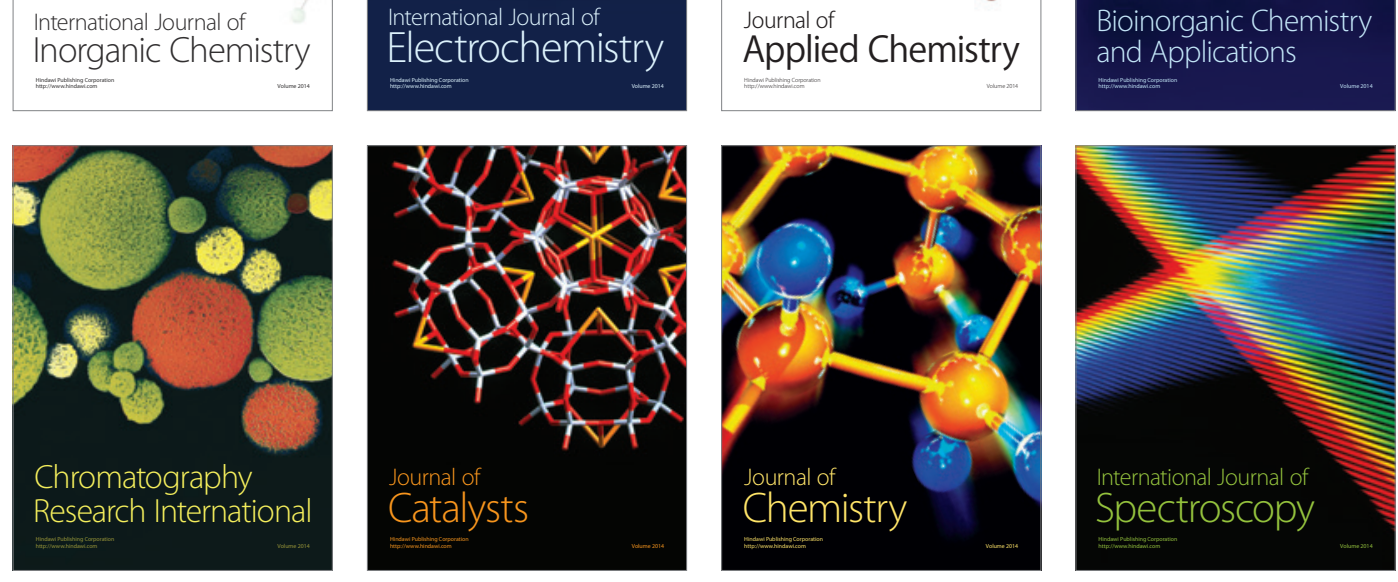